\title{
An investigation of the most waste-prone materials and waste causes in prefabricated steel structure building projects
}

\author{
Babak Rahmani Mirshekarlou ${ }^{\mathrm{a}, *}$, Irem Dikmen $^{\mathrm{b}}$, M.Talat Birgonul ${ }^{\mathrm{b}}$ \\ ${ }^{a}$ PhD Candidate, Department of Civil Engineering, Middle East Technical University, Ankara, 06800, Turkey \\ ${ }^{b}$ Professor, Department of Civil Engineering, Middle East Technical University, Ankara, 06800, Turkey
}

\begin{abstract}
Prefabrication is the shifting of construction activities from traditional practices, with high level of waste, to industrial processes with minimum waste generation. Therefore, it is considered as one of the major improvements to minimize waste generation in the construction industry. However, the prefabrication process itself is associated with significant amount of material wastage; which increases the total project cost and time with negative environmental impacts. In order to take efficient measures in reducing the amount of waste at source, which is the initial step in waste management, it is essential to identify the most waste-prone materials and investigate the main sources of waste generation. The current paper presents initial findings of an on-going research on development of a process model as well as a decision support tool to predict and manage waste in prefabricated steel structure projects. An investigation has been carried out in collaboration with the Turkish prefabricated steel structure building companies to identify the most waste-prone materials and the main sources of waste generation. A mixed research method incorporating qualitative and quantitative approaches were adopted during the initial phase of the on-going study. A classified list of potential waste causes and a set of materials were formulated by a detailed literature review, studying real project records in a company and by interviewing with experts in the sector. A multi-phase questionnaire survey has been administrated to more than 30 professionals to learn about their perceptions on waste-prone materials, their sources and factors plugging the way of effective waste management within the prefabrication sector in Turkey.

The questionnaire results indicate that, sealing materials, dry wall boards, heat insulation materials, cables and paints are the five most waste-prone material groups. Also, the main sources of waste generation are identified; which reveals the dynamic nature of material waste causes. After the discussion of questionnaire findings, it would be proposed that considering the different sources of waste generation, impacts on project performance and mitigation strategies, an efficient waste management process model and a support tool should be developed for the Turkish prefabricated building companies in order to monitor and control waste generation.
\end{abstract}

(C) 2018 The Authors. Published by Diamond Congress Ltd., Budapest University of Technology and Economics Peer-review under responsibility of the scientific committee of the Creative Construction Conference 2018.

Keywords: Construction; Material Waste; Prefabrication; Waste Causes.

\section{Introduction}

Construction industry produces significant amount of waste arising from construction activities in diverse form of debris including inert and organic materials or a mixed combination. The common perception about the material waste in construction is generally focuses on the direct material disposals from construction sites as debris [1], however there is a significant type of waste, known as indirect waste, that should be taken into account when studying the material waste in construction industry. Skoyles [2] categorizes wastes in two principal types, including direct and indirect wastes. According to this classification, direct wastes are the physical loss and unrepairable damages of material which 
incorporates both physical and monetary losses, and generally needs disposal and replacement of wasted material. On the other hand, indirect wastes are generally originating from unnecessary material substitutions, excessive use of material and errors during constructions, which only cause monetary losses without physically damage of material. Construction and Demolition wastes are divided into three categories according to the generation phase by Wu et al. [3]: Construction Wastes (CW), Renovation Waste (RW) and Demolition Waste (DW) which generally composed of inert materials with little damage to the environment (e.g., concrete, bricks, etc.). These inert materials are generally wasted in traditional construction methods by wet trade activities; however, some hazardous material components are also generated which requires properly recycling or disposal processes with more cost and environmental effects. The prefabricated industry produces less inert wastes and more hazardous materials therefore waste reduction at source should be more considered. Various definitions have been proposed for waste in literature, Formoso et al. [4] defines the waste as any inefficiency in the utilization of equipment, materials, labour or capital which leads to the use of quantities larger than necessary amounts. The concept of waste in construction covers a wide range of subjects including operations and resources; however, the focus of this study is on the waste of material. Regardless of the waste type, material wastage has considerable economic, environmental and social impacts as well as negative effects on project time, productivity and efficiency.

Materials are the major components of construction projects and constitute the significant portion of project budget. Yu et al. [5] declare that material involves $50 \%$ to $80 \%$ of total cost in building projects. When waste occurs, usually new purchases should be done to cover the lack of wasted materials, therefore, any direct and indirect costs associated with material procurement will be reflected as cost overrun in total project budget. Ameh and Daniel [6] found that the material wastage contributes about $21 \%$ to $30 \%$ of cost overruns in construction projects.

In addition to the cost effect of material waste, the environmental impacts of wastes are also considerable. It is obvious that the construction industry, due to its nature, is environmentally unfriendly [5],[7] meaning that the majority of construction and side activities, from material extraction and production to handling and execution, have inherently environmental impacts, which can be escalated with inefficient management of waste. The construction industry consumes energy the nonrenewable natural resources, directly or in production of the construction materials. Udayangani et al. [8] claim that $40 \%$ of raw stone, gravel and sand as well as $25 \%$ of virgin wood are consumed in construction industry every year in the world. Therefore, the waste of material leads to depleting theses resources during a medium or long-term period and converts them to the construction debris which in turn results in soil and water contamination. These contaminations effects the social health and destroys the public image of the industry [7]. Nowadays, environmental impacts of material waste, due to the wide range of its side effects, are significantly emphasized by researchers in compare with other negative results. Waste usually cause activity delays due to the unplanned waiting time for material repurchasing. Several studies demonstrate the material waste as the major source of schedule delays and low productivity in construction projects [9],[10],[11].

In order to minimize the above-mentioned impacts of material waste and increase the cost, time and environmental performances of projects, it is essential to manage the waste properly during the project life cycle. Poor waste management will lead to rising amount of waste and direct disposal to landfills therefore, cause to extreme impacts on project performance and environment. According to the "Waste Management Hierarchy", the waste management options are prioritized as avoidance, minimization, recycling, treatment and disposal, the most preferred options with highest priorities are avoidance and minimization of waste generation at source [12]. Waste recycling, treatment or disposals have greater cost and environmental effects; therefore, the waste reduction options including avoidance and minimization are preferred as more environmentally friendly and cost-effective methods. However, since the waste generation at construction is not completely preventable and certain levels of unavoidable waste is generally remains, waste reduction at source and proper recycling of residual wastes are considered as the main objectives of sustainable management of wastes in construction [13].

Since the traditional construction methods produce unacceptable level of waste, therefore, shifting the conventional methods to industrial and prefabricated systems is suggested as one of the waste reduction technics at source [14]. Prefabrication reduces the waste generation by minimizing the share of wet-trade and labour intensive activities and increasing the industrial production ratio in compare with traditional methods. Prefabrication also facilitates the implementation of lean production by providing the integrated design and production system which is the main distinction between construction and industry. Prefabrication and industrialization of construction activities, along with the waste minimization in project execution, provides various advantages over conventional construction, including time and cost savings quality and safety improvements. However, the prefabrication itself is associated with significant amount of material waste; which increases the total project cost and time and reduces the final product quality with various environmental impacts. In case of poor waste management in prefabrication, the relative advantages of cost, 
time and quality will be lost; besides, due to the type of materials used in prefabrication, the recycling and disposal of wasted materials will be more costly and hazardous in compare with traditional construction. Wet-trade construction methods mostly consumes traditional and inert materials; however, the prefabrication generally uses modern construction materials which are mostly the product of complex chemical refinement processes on raw materials. These types of materials although has valuable properties, however, they contain chemical admixtures to provide their enhanced performance and service life; therefore, the recycling or disposal process of these kinds of materials will be more expensive and environmentally hazardous.

Considering the time, cost, quality and environmental advantages of prefabrication above traditional construction, and regarding to the remarkable impact of waste on whole advantage factors, it is obvious that if the waste in prefabrication would not be managed properly, it will not be preferred in construction projects. Therefore, the impacts of poor waste management in prefabrication will be more detrimental than traditional construction and excessive endeavor shall be made to improve the waste management performance in prefabricated construction projects.

In this paper, we will report preliminary findings of an on-going study on management of waste in prefabricated steel structure building projects and point out the need for a systematic waste management process as well as a tool in the prefabricated construction sector.

\section{Background and research motivation}

During the late decades, in parallel with rapid economic developments in the world, the waste has been arisen as the main problem of the construction industry, and due to the critical role of waste management in sustainable development and lean construction, it becomes as an attractive research topic in recent years. Building sector in all countries incorporates a considerable amount of material waste generation; in the US, approximately 136 million tons of building-related wastes are generated annually [15]; this amount is reported around 70 million tons in UK [16] and about 14 million tons in The Netherlands accounting for about $26 \%$ of all waste generation in the country. It also found that construction wastes contribute for around $40 \%$ of municipal solid wastes in China [17], 20\% - 30\% in Australia and $20 \%$ in the US [18]. Consequently, the majority of current studies covers the material wastage in building construction projects mostly executed using traditional materials and methods which produces unacceptable level of waste. Since the type of materials used in the conventional construction as well as the construction practices are mostly different than those utilizing in prefabricated methods, therefore generalizing the findings of these studies in prefabrication would not be fully applicable.

On the other hand, the geographic distribution of existing studies are generally concentrated on developed countries rather than in developing economies like Turkey; indicating the importance degree of waste management in developed economies [19]. Since the waste generation in each country is significantly affected by regional practices, materials, regulations and other local specific factors, the existing studies cannot completely reflect the state of waste management in other regions, therefore a huge gap is existing for the waste management studies in regional scales essentially in developing countries like Turkey. Although the construction sector in Turkey constitutes a significant share of national economy and Turkish contractors are among the main corporations of global construction industry, however, there are few studies dealing with construction waste management in Turkey. Considering the prefabrication industry as one of the main ways of industrialization of construction with lower time, cost and waste generation and regarding to the growing need of Turkish contractors to implementation of lean construction concept for achieving strategic advantages in global markets, the prefabrication industry is trending in recent years.

It is generally accepted that the basic advantages of prefabrication can be adversely affected by poor waste management; therefore, the need for efficient waste management is more critical in prefabrication industry in order to achieve the planned performances under lean construction concept. Investigating the sources of waste generation including the identification of wasteful materials and the waste causes are regarded as the prerequisite step for successful implementation of waste reduction in prefabricated construction industry. Besides, improving the waste management performance in Turkish construction industry by investigating the current state of waste management in prefabricated industry as a growing sector not only benefits the national development but also increases the competitiveness of Turkish contractors in global markets. The existing prefabricated building industry in Turkey is generally include concrete and steel structure buildings the focus of this study is prefabricated steel structure building projects. 


\section{Literature review}

Limited studies are available on material waste management in construction industry. Most of the available studies have been focused on waste quantification, source investigation and recycling, mainly in traditional construction and few studies have been done on waste reduction.

Skoyles [2] carried out the first extensive study on material wastage in UK building industry by direct on-site observations and investigating of project records of 114 building projects from 1960 to 1970. They examined the waste generation rate for 37 different materials and reported that the percentage of material wastage in weight ranged from $2 \%$ to $15 \%$ according to the estimated amount of materials in design stage. The study revealed that the actual material losses are mostly higher than initial estimations; also, the waste rates for each material are extremely variable in different construction sites indicating that most of the existing wastes are avoidable. They also concluded that the major material wastes arise from poor material management on site, incorrect material unloading, poor ground conditions, inadequate transportation equipment and unsuitable packaging. They either reported that the wastes are generally the result of occurrence of multiple causes, rather than single events. In order to reduce the environmental impacts of construction wastes and restrict the rising demand for limited disposal areas in Hong Kong, a study was conducted by The Hong Kong Polytechnic and Hong Kong Construction Association [20] investigating the ways of waste reduction at source. The construction processes with high potential to waste generation in 32 construction sites were monitored during June 1992 to February 1993 and discussed the relative importance of the waste of six different materials including: premixed concrete, steel reinforcement, mortar, bricks and blocks, ceramic tiles, and wood. They also declared that the average waste of premixed concrete in 14 sites were $11 \%$ varying from $2.4 \%$ to $26.5 \%$.

A research was conducted by Bossink and Brouwers [18] in The Netherlands and investigated the waste of seven materials in five housing projects between April 1993 and June 1994; and reported that direct wastes were ranged from $1 \%$ to $10 \%$ in the weight of purchased material. Gavilan and Bernold [21] reported the results of an empirical study in US on analyzing three processes including masonry foundations, timber frames and sheetrock drywall in five homes at four construction sites. Residual scraps of bricks, blocks, lumber and sheetrock panels remaining from cutting, nonreusable consumables of wood and packaging and improper handling were identified as the major sources of waste. Pinto [22] carried out a single case study on direct and indirect waste of materials on a residential building project in Brazil using the project records; and found that the percentage of wasted materials varies from $1 \%$ to $102 \%$ in weight, based on the estimated amounts in design stage. The results also revealed the importance of indirect wastes in compare with direct wastes, for instance the indirect waste of mortar were found as much as $85 \%$ of the designed quantities. In Brazil, a detailed study were conducted by Formos et al. [1] in two time phases to explore the main causes of material wastage as well as to investigate the guidelines for waste prevention. The first study monitored 7 materials in 5 projects during 1992-1993 and the second study investigated 18 materials in 69 construction sites during 1996-1998. Some values for the waste rate of investigated materials were found, and the main causes of waste generation in the sector were discussed. The results indicated that the waste of materials in the Brazilian building industry was fairly high and varies significantly across different projects.

From the literature review, it is observed that the current data on material waste in the building industry is relatively scarce and comparing the results of these studies is difficult due to the locational and technical differences between studies, which strongly affects the outcomes. However, it is clearly notable that the level of waste generation in traditional construction methods are significantly high and variable meaning that the waste in most cases is avoidable. Several studies suggest taking actions to reduce the waste generations at source by improving the processes rather than dealing with generated wastes by recycling or reuse. Some studies [23] [24] report that concern about the extra cost of recycling and the quality of recycled materials are key barriers to the promotion of recycling practices in construction. Modular design and prefabricated construction is proposed as one of the effective and feasible methods for process improvement and waste reduction at source. Baldwin et al. [25] confirm that off-site prefabrication of building elements can effectively reduce the waste generation on site. Lachimpad et al. [26] compared the waste generation by three different construction methods in high-rise buildings in Malaysia and found that Industrialized Building Systems are most waste efficient method with a waste generation rate of 0.016 tons $/ \mathrm{m}^{2}$. Wang et al. [27] investigated the factors affecting construction waste minimization at design stage and suggested to develop modular design and prefabrication of building components as one of the more effective ways in waste minimization. Vivian et al. [28] also compared the average waste level of materials in two groups of projects, adopting conventional construction and prefabrication, and found that the wastage level in several trades including: concreting, rebar fixing, bricklaying, tiling and plastering have been reduced, however new wastes have been occurred due to the utilization of new kind of materials in prefabrication (e.g. drywall). A study by Tam et al. [29] suggested that construction waste generation can be fully avoided by using 
prefabrication technologies. Although the prefabrication promotes the project performance in time, cost, quality and safety however, waste production may not be completely avoided if the material wastage would not be managed properly. This concern is revealed by Jaillon et al. [30] reporting that prefabrication can only provide about 52\% reduction in average waste rates.

As a result, to prevent the waste generation in prefabrication, there is a need to identify the sources of existing wastes. There are several studies in different countries to identify the sources of wastes in construction but the focal point of these studies are traditional constructions. Bossink and Brouwers [18] investigated the sources of construction waste in The Netherlands by categorizing 31 sources of waste under 6 main categories including: design, procurement, materials handling, operation, residual and other non-categorized factors. They identified that the main causes of material wastage are related to design, material supply, poor handing in transportation and storage. Adewuyi and Odesola [31] assessed the level of contribution of several factors to construction material waste generation in Nigeria. They identified 74 waste causes and grouped them under 8 main categories including: design and documentation, materials procurement, materials management on site, materials handling, storage and transportation, on-site operations, environmental conditions, site management and practices, and site supervision. The results revealed that reworks due to non-conformance to specifications, waste from cutting uneconomical shapes, and design changes and revisions were the first three highest contributors to material waste. Umar et al.[32] identified 40 causes of waste in Malaysian residential projects and grouped them into seven categories including: site operation, on-site management and planning, material storage and handling, design and documentation, transportation, procurement and external factors and revealed that on-site operation activities rank as the most important sources of waste. Gavilan and Bernold [21] considered 12 factors as main causes of construction waste generation. The study pioneered the grouping of such factors into various categories. Ekanayake and Ofori [33] examined and discussed 27 factors as causes of construction waste. Poon et al. [14] conducted a research in Hong Kong and identified 13 factors that cause material waste in construction. Garas et al. [34] also considered 10 important factors in the generation of construction waste in Egyptian construction industry.

Limited studies exist on construction waste management in Turkey; Polat and Ballard [35] assessed 14 factors in their study to identify the main causes of material waste in Turkish construction industry. Esin and Cosgun [36] conducted a survey among 180 homeowners from different parts in Istanbul to investigate the construction material waste generation due to modifications on residential buildings and proposed to use standard and modular structures for building materials to be easily dismantled without damaging. They also find that one of the sources of frequent modifications is the poor material and labor quality.

\section{Research objectives and methodology}

On-site processes and the basic materials used in prefabricated building projects are mostly different than those in traditional constructions, which have been investigated in previous studies. Therefore, this study aims to identify the most waste-prone materials and investigate the high priority waste causes in prefabricated building projects.

A mixed research method incorporating qualitative and quantitative approaches were adopted in this research. The methodology includes investigating project records, literature review, interview with professionals, and questionnaire surveying. The initial data from project records and literature review is comprising the basis of interviews; then, all the information collected from interviewing and other resources organized and arranged properly in the form of questionnaires; finally, the data gathered from questionnaire surveying is being analyzed. Since the objective of the research complies with the questionnaire sample surveying method, therefore, this method was used as quantitative analyzing approach in the study.

\subsection{Preparation of a list of waste-prone materials}

A list of basic material groups was prepared using the data collected from 4 prefabricated steel structure building projects, undertaken by Turkish companies within Turkey and 2 other countries. The bill of quantities and material purchase lists were investigated and a primary list of 47 material groups was prepared considering the relative cost of each group to total material cost, and also with regarding to the material potential for being wasted. The identified materials were classified under 3 different categories including: building materials, mechanical materials and electrical materials. The number of material groups was reduced to 42 by excluding 5 sets from the initial list, considering the minor waste potential or minor cost effect in projects, after interviewing with 9 professionals from prefabricated 
construction industry. As it is shown in Table 1, Table 2, and Table 3 the final material list includes 27 building materials, 9 mechanical materials and 6 electrical materials.

Table 1. Building material groups

\begin{tabular}{|c|c|c|c|}
\hline Ranking & Building material group & $\sum \mathrm{w}$ & RII \\
\hline 1 & Sealing materials (silicon, etc.) & 132 & 0,78 \\
\hline 2 & Gypsum board & 116 & 0,68 \\
\hline 3 & Fiber cement board & 104 & 0,61 \\
\hline 4 & Heat insulation (rockwool - XPS - glass wool) & 102 & 0,60 \\
\hline 5 & Paint & 98 & 0,58 \\
\hline 6 & Fasteners/ connection elements & 96 & 0,56 \\
\hline 7 & Plaster (gypsum \& others) & 96 & 0,56 \\
\hline 8 & Ceramic tile & 96 & 0,56 \\
\hline 9 & Un-structural concrete (screed \& others) & 94 & 0,55 \\
\hline 10 & Door handles and accessories & 92 & 0,54 \\
\hline 11 & Waterproofing material & 92 & 0,54 \\
\hline 12 & PVC flooring & 88 & 0,52 \\
\hline 13 & Window handles and accessories & 88 & 0,52 \\
\hline 14 & Wood (OSB - timber \& plywood) & 84 & 0,49 \\
\hline 15 & Premixed structural concrete & 84 & 0,49 \\
\hline 16 & Carpet flooring & 84 & 0,49 \\
\hline 17 & Sandwich panels & 80 & 0,47 \\
\hline 18 & Cast/cut stone & 78 & 0,46 \\
\hline 19 & Steel reinforcement & 78 & 0,46 \\
\hline 20 & Laminated parquets & 78 & 0,46 \\
\hline 21 & Aluminum board/tiles & 76 & 0,45 \\
\hline 22 & Vapor barrier & 74 & 0,44 \\
\hline 23 & Wooden doors & 74 & 0,44 \\
\hline 24 & Steel profiles/ structural elements & 66 & 0,39 \\
\hline 25 & Laminated separation panels & 64 & 0,38 \\
\hline 26 & PVC window & 56 & 0,33 \\
\hline 27 & Aluminum window & 52 & 0,31 \\
\hline
\end{tabular}

Table 2. Electrical material group

\begin{tabular}{clcc}
\hline Ranking & Electrical material group & $\sum \mathrm{w}$ & $\mathrm{RII}$ \\
\hline 1 & Cables (LV - LC - MV) & 102 & 0,60 \\
2 & PVC cable conduits \& pipes & 98 & 0,58 \\
3 & Cable trays & 88 & 0,52 \\
4 & Switch, sockets and electrical installations & 86 & 0,51 \\
5 & Electrical equipments & 78 & 0,46 \\
6 & Lighting units & 74 & 0,44 \\
\hline
\end{tabular}


Table 3. Mechanical material group

\begin{tabular}{clcc}
\hline Ranking & Mechanical material group & $\sum \mathrm{w}$ & $\mathrm{RII}$ \\
\hline 1 & PVC pipes and fittings & 98 & 0,58 \\
2 & Pipe heat insulations & 96 & 0,56 \\
3 & PPRC pipes and fittings & 90 & 0,53 \\
4 & Sanitary/ bathroom accessories & 84 & 0,49 \\
5 & HDPE pipes and fittings & 82 & 0,48 \\
6 & Air ducts and fittings & 82 & 0,48 \\
7 & Sanitary wares & 82 & 0,48 \\
8 & Steel pipes and fittings & 78 & 0,46 \\
9 & Mechanical equipments & 58 & 0,34 \\
\hline
\end{tabular}

\subsection{Identifying waste causes}

A categorized list of potential waste causes, including 49 items were identified through a detailed literature review and classified under 5 categories. The prepared list was discussed by 9 sector professionals and some specific waste causes that were not identified in literature were added and some causes with same concepts were merged together; ultimately the final list with 46 waste causes and 6 different categories was prepared as shown in Table 4 .

\subsection{Questionnaire design}

Arranging the final results of interviews, and considering the length of the surveys, a two-phase questionnaire was designed and distributed between sector professionals to learn about their perceptions about wasteful materials and waste causes. The first phase of survey was designed to elicit the perception of respondents about the most waste-prone materials for three disciplines including: building, electrical, and mechanical works; and the second phase were seeking the answers for most critical waste causes. The questionnaires consisted of two sections, the first section was related to the general information of respondents and their company profile; like, company size and their experience in prefabricated construction industry. In second section, the respondents were required to identify their perceptions about most waste-prone materials and waste causes in first and second phases respectively. The first phase of the survey asks the respondents to evaluate the 42 identified materials (Table 1, Table 2, Table 3) according to their level of wasteproneness using a five-point Likert system ranged from 1 to 5 ; representing: $1=$ very low; $2=$ low; $3=$ average; $4=$ high; and $5=$ very high. After the results of the first phase were analyzed and the most wasteful materials were identified for each discipline; the respondents required to evaluate the waste causes in general and for most wasteful material groups in each discipline. The survey in second phase were asking the respondents to rank the degree of contribution of 46 identified waste causes (Table 4) in waste generation based on their experience in prefabricated steel structure projects according to the given five-point Likert scale representing $1=$ very little; $2=$ little; $3=$ moderate; $4=$ great; and $5=$ extreme.

\subsection{Sampling and data collection}

A representative sample is a small set of a larger group that adequately reflects the characteristics of its population as a whole. Statistical methods are generally used for designing the representative sample in questionnaire surveying, to enable the generalization of findings to the entire population [37]. For this purpose, 11 Turkish companies with national and international experiences in steel structure prefabricated building projects were identified using information obtained from Turkish Contractors Association (TMB). 73 questionnaires were sent by Email to professionals from these companies which were specified using business network connections and professional social networks such as Linkedin. 34 responses for first phase and 45 replies for second phase were collected from 5 participant companies. 
Table 4. Categorized material waste causes

\begin{tabular}{|c|c|}
\hline Waste category & Waste cause \\
\hline Design & $\begin{array}{l}\text { Poor design and details } \\
\text { Poor estimations } \\
\text { Poor specifications } \\
\text { Changes in designs and specifications } \\
\text { Complexity and low constructability of design } \\
\text { Poor interdisciplinary design integration } \\
\text { Improper/ wrong material selection or substitution } \\
\text { Ignorance of material specifications in designs }\end{array}$ \\
\hline Procurement & $\begin{array}{l}\text { Ordering errors (quality/quantity errors, wrong selection/substitution) } \\
\text { Supplying errors by suppliers (quality/quantity errors) } \\
\text { Early or late delivery } \\
\text { Defective/rejected products } \\
\text { Ordering limitations applied by suppliers (quantity/quality limitations) }\end{array}$ \\
\hline Transportation & $\begin{array}{l}\text { Poor loading and unloading } \\
\text { Inappropriate packing for transportation } \\
\text { Multiple shipment/ transportation points } \\
\text { Accident during transportation } \\
\text { Poor site accessibility/ road condition }\end{array}$ \\
\hline Storage and distribution & $\begin{array}{l}\text { Poor/improper handling and distribution on site } \\
\text { Poor/improper storage and protection } \\
\text { Unpacked/ improper packaging of materials } \\
\text { Multiple/ unnecessary relocating or Handling } \\
\text { Excessive/ unnecessary inventories } \\
\text { Poor site storage capacity } \\
\text { Accidents during storage and distribution } \\
\text { Handling equipment failure (breakdown or malfunctioning) } \\
\text { Untraceable/ left-over materials on site } \\
\text { Poor stock management }\end{array}$ \\
\hline Construction & $\begin{array}{l}\text { Using poor quality/ wrong material } \\
\text { Poor/ wrong execution of work } \\
\text { Damages by subsequent trades } \\
\text { Excessive/ unoptimized cutting (conversion waste) } \\
\text { Accidents during construction } \\
\text { Excessive use of material } \\
\text { Overproduction } \\
\text { Ignorance of designs/ method statements during construction } \\
\text { Unavoidable process waste }\end{array}$ \\
\hline External waste affecting factors & $\begin{array}{l}\text { Poor planning and scheduling } \\
\text { Poor waste management } \\
\text { Poor supervision and control } \\
\text { Poor project contracting/ subcontracting } \\
\text { Unfavorable weather conditions } \\
\text { Natural/ manmade disasters (e.g. earthquake, floods, war, etc.) } \\
\text { Unknown site conditions } \\
\text { Theft and vandalism } \\
\text { Unskilled/ unexperienced labour }\end{array}$ \\
\hline
\end{tabular}


The majority of companies (60\%) are large companies with more than 250 employees; and the remaining (40\%) are medium size companies with employees between 50 to 250 people. $80 \%$ of companies have more than 20 years of experience in national and international prefabricated building projects which demonstrates their understanding of the construction waste in Turkey and other countries. Moreover, $67 \%$ of participants have more than 10 years of experience in prefabrication which means that they are professionals with significant knowledge about material wastes and sources of waste generation in construction sites. Regarding to the profile of targeted companies and respondents, it is obvious that the representative sample has a uniform and homogenous composition; also, it is expected that the responses will be adequately consistent; therefore, as it is declared by De Vaus [37], the relatively small sample size can suffice in a homogeneous population in which most people will answer a question similarly. Besides, the more uniform and consistent a population is, the smaller a sample that can be drawn from it for a research purpose will be [38]. Considering the level of participation from $45 \%$ of targeted companies (46.6\% in phase $1 ; 61.6 \%$ in phase 2 ) and the uniformity of the respondents and expected consistent answers from participants, this level of participation for sample study would be sufficient.

\section{Data analysis}

To determine the relative ranking of the most waste-prone materials and waste causes, the responses collected from surveys were evaluated according to the Relative Importance Index (RII) using the following equation:

$$
R I I=\frac{\sum W}{A \times N} \quad(0 \leq R I I \leq 1)
$$

Where:

W: The weight given to each factor by the respondents and ranges from 1 to 5 ,

A: The highest weight and,

$\mathrm{N}$ : The total number of respondents

The Relative Importance Index (RII) was calculated for each material type and for each cause; the materials and causes were ranked according to the value of RII. The results of material ranking based on RII, are demonstrated for building, electrical and mechanical materials in Table 1, Table 2, and Table 3 respectively. According to the results, sealing materials, wall and ceiling boards (gypsum and fiber cement boards), heat insulation materials, and paint, are the most five waste-prone building materials in prefabricated steel structure projects. In addition, cables in electrical material group and PVC pipes and fittings in mechanical material group has the greatest RII and are evaluated as the most wasteful materials by respondents.

Based on the results of first phase of survey, one material from each discipline including "wall and ceiling boards", "pipes and fittings", and "cables" were selected considering their RII value and cost and quantity in prefabricated projects, to investigate the related waste sources in second phase of survey.

The respondents in second phase, were asked to evaluate the waste causes in general and for selected three materials either. According to the results, demonstrated in Table 5 and Table 6, "poor site storage capacity" and "poor stock management" are the most critical waste causes in general evaluation. On the other hand, "multiple/ unnecessary relocating or handling" of material is identified as the highest rated waste cause for "wall and ceiling boards" whereas, "unpacked/ improper packaging of materials" and "Damages by subsequent trades" has the highest importance in waste generation of "pipes and fittings" and "cables" respectively. 
Table 5. General evaluation of material waste causes

\begin{tabular}{cllc}
\hline Ranking & Waste causes & $\sum \mathrm{w}$ & $\mathrm{RII}$ \\
\hline 1 & Poor site storage capacity & 184 & 0,82 \\
2 & Poor stock management & 175 & 0,78 \\
3 & Poor/ improper storage and protection & 168 & 0,75 \\
4 & Unskilled/ unexperienced labour & 157 & 0,70 \\
5 & Poor estimations & 155 & 0,69 \\
6 & Poor design and details & 153 & 0,68 \\
7 & Unpacked/ improper packaging of materials & 153 & 0,68 \\
8 & Multiple/ unnecessary relocating at site & 152 & 0,68 \\
9 & Unfavorable weather conditions & 151 & 0,67 \\
10 & Changes in designs and specifications & 151 & 0,67 \\
\hline
\end{tabular}

Table 6. Five most important waste causes for different materials

\begin{tabular}{clc}
\hline Ranking & Waste causes & RII \\
\hline Wall and ceiling boards & 0,73 \\
1 & Multiple/ unnecessary relocating or Handling & 0,71 \\
2 & Poor/ improper storage and protection & 0,71 \\
3 & Poor site storage capacity & 0,70 \\
4 & Excessive/ unoptimized cutting (conversion waste) & 0,69 \\
5 & Unskilled/ unexperienced labour & \\
Pipes and fittings & 0,89 \\
1 & Unpacked/ improper packaging of materials & 0,87 \\
2 & Untraceable/ left-over materials on site & 0,82 \\
3 & Poor interdisciplinary design integration & 0,82 \\
4 & Ignorance of material specifications in designs & 0,78 \\
5 & Ordering errors (quality or quantity errors, wrong selection or substitution) & \\
Cables & & 0,83 \\
1 & Damages by subsequent trades & 0,83 \\
2 & Ignorance of designs/ method statements during construction & 0,78 \\
3 & Poor planning and scheduling & 0,75 \\
5 & Theft and vandalism & 0,70 \\
\hline
\end{tabular}

\section{Discussion of findings and conclusions}

The construction processes in prefabrication are mostly industrialized, meaning that, depending on the level of prefabrication, the whole or a portion of building elements are fabricated in production plants which are generally apart from construction sites. Therefore, proper packaging, transportation and storage of manufactured elements are significantly important in this sector. The most common prefabricated elements are wall and roof panels, structural elements, suspended ceilings, doors and windows and the major construction activities on site focus on assembly and installation of these elements. Considering this method of construction, the results of the ranking of most waste-prone 
materials and critical waste causes can be discussed accordingly. The study confirms that sealing materials are the most wasteful material in prefabrication; indicating that water leakage is a common problem of this industry as it is mentioned by Poon et al [14] and Tam et al [39]. Due to the problems that arise from poor integration of nonstandardized designs with production and on-site assembly, sealing of assembled elements seems to be one of the most challenging obstacles in prefabrication which leads to excessive use of sealing materials. Gypsum and fiber cement boards are ranked as second and third most waste-prone materials respectively in Table 1 . These are the major covering materials in prefabricated wall and roof elements; therefore, as it is mentioned in Table 6, multiple relocating and poor storage and protection at construction sites may lead to increasing damages on them.

Cables are identified as the most waste-prone material in electrical material group, which are affected by damages from other trades, rout changes by ignoring design during construction and theft or damage due to improper storage and protection on site. In mechanical group of materials, PVC pipes and fittings are evaluated as the most waste-prone materials that improper packing, left-over on site and poor interdisciplinary design integration are the most important causes for their waste generation.

The results of the study reveal that, the most waste-prone materials in prefabrication industry are totally different than those in traditional construction. Considering the chemical composition of these materials, it is observed that in contrast to traditional construction with inert combination of wastes, the wasted materials in prefabrication are mostly made from synthetic materials. The recycling cost and environmental effect of improper disposal of these materials are extremely high; therefore, efficient management of material waste in prefabrication is considerably important.

In the light of the findings above, it is obvious that the most 10 important waste causes belong to three waste categories identified in Table 4 . Accordingly, $50 \%$ of waste causes are originated from "storage and distribution", $30 \%$ from "design" and $20 \%$ of waste sources are related to "external affecting factors" such as unskilled labour and weather conditions. Therefore, proper packing of materials for long-distance transportation and appropriate storage and protection against diverse weather conditions on construction sites are the major actions should be taken for waste reduction in prefabrication. Besides, standardization of designs and integration of design, production and on-site assembly works, with exact consideration of site conditions will improve the quality of design and details. Moreover, the amount of revisions after design phase must be reduced to overcome the waste generation, arising from on-site variations, for this purpose the customer needs and requirements must be exactly identified and incorporated in designs, also the interdisciplinary integration should be improved in designs by using Building Information Modeling (BIM). Application of BIM in design process not only reduces the clashes by improving the accuracy of design and details, but also increases the validity of quantity estimations which is found as one of the substantial waste causes as indicated in Table 5.

The study also confirms that the waste can be originated from different sources for various materials. The results of waste causes ranking in general and specifically for three different materials shown in Table 5 and Table 6 , indicates the variability and flexibility of waste causes in each case. Therefore, since the waste is not completely avoidable and whole sources of waste cannot be managed properly, it would be more efficient to focus on the most waste-prone materials and significant waste causes to achieve more effective waste management results. Also, the project management team must be able to deal with the waste sources prior to their occurrence, or at the earliest time they are recognized during project life cycle. For this purpose, the research team is developing a tool for facilitating the tracking of the waste generation by controlling the related waste sources and recording the data while the project is going on. This will provide a corporate knowledge from previous projects for efficient prediction of possible waste generation sources prior to project commence and facilitates an effective waste prediction and management during project execution. Since late preventive actions would be more costly, or in some cases impossible, this tool is expected to be useful for timely management of waste in prefabricated construction projects; and will lead to increase in the efficiency of projects by enhancing the time, cost and environmental performances.

\section{References}

[1] C. T. Formoso, L. Soibelman, C. De Cesare, and E. L. Isatto, "Material Waste in Building Industry: Main Causes and Prevention," J. Constr. Eng. Manag., vol. 128, no. 4, pp. 316-325, Aug. 2002.

[2] E. R. Skoyles, "Materials wastage - a misuse of resources," Batim. Int. Build. Res. Pract., vol. 4, no. 4, pp. 232-243, 1976.

[3] Z. Wu, A. T. W. Yu, L. Shen, and G. Liu, "Quantifying construction and demolition waste: an analytical review.," Waste Manag., vol. 34, no. 9, pp. 1683-92, Sep. 2014. 
[4] C. T. Formoso, E. L. Isatto, and E. H. Hirota, "Method for Waste Control in the Building Industry," in Proceedings IGLC-7, 1999, pp. 325-334.

[5] A. T. W. Yu, C. S. Poon, A. Wong, R. Yip, and L. Jaillon, "Impact of Construction Waste Disposal Charging Scheme on work practices at construction sites in Hong Kong," Waste Manag., vol. 33, no. 1, pp. 138-146, 2013.

[6] A. O. John and D. E. Itodo, "Professionals' views of material wastage on construction sites and cost overruns," Organ. Technol. Manag. Constr. An Int. J., vol. 5, no. 1, pp. 747-757, 2013.

[7] H. Yuan, A. R. Chini, Y. Lu, and L. Shen, "A dynamic model for assessing the effects of management strategies on the reduction of construction and demolition waste," Waste Manag., vol. 32, no. 3, pp. 521-531, 2012.

[8] K. Udayangani, A. Dilanthi, H. Richard, and R. Raufdeen, "Attitudes and perceptions of construction workforce on construction waste in Sri Lanka," Manag. Environ. Qual. An Int. J., vol. 17, no. 1, pp. 57-72, 2006.

[9] A. Makulsawatudom and M. Emsley, "Factors Affecting the Productivity of the Construction Industry in Thailand: The Project Managers' Perception," in Proceedings, Construction Research Congress, ASCE, 2003, pp. 41-50.

[10] L. C. Bell and George Stukhart, "Costs and benefits of materials management systems," J. Constr. Eng. Manag., vol. 113, no. 2, pp. 22-34, 1987.

[11] L. C. Bell and G. Stukhart, "Attributes of Materials Management Systems," J. Constr. Eng. Manag., vol. 112, no. 1, pp. 14-21, 1986.

[12] C.-L. Peng, D. E. Scorpio, and C. J. Kibert, "Strategies for successful construction and demolition waste recycling operations," Constr. Manag. Econ., 1997.

[13] Y. Yang and L. Shi, "Integrating environmental impact minimization into conceptual chemical process design - a process systems engineering review," Comput. Chem. Eng., vol. 24, no. 2-7, pp. 1409-1419, 2000.

[14] C. Poon, A. Yu, and L. Ng, A guide for managing and minimizing building and demolition waste. Dept. of Civil \& Structural Engineering, Hong Kong Polytechnic University, 2001.

[15] P. Sandler, K., Swingle, "OSWER Innovations Pilot: Building Deconstruction and Reuse," 2006. [Online]. Available: http://www.epa.gov/oswer.

[16] DETR, "Building a Better Quality of Life: A Strategy for more Sustainable Construction," no. April. Department of the Environment, Transport and the Regions: London, 2000.

[17] J. Wang, X. Kang, and V. Wing-Yan Tam, "An investigation of construction wastes: an empirical study in Shenzhen," J. Eng. Des. Technol., vol. 6, no. 3, pp. 227-236, Oct. 2008.

[18] B. A. G. Bossink and H. J. H. Brouwers, "Construction Waste: Quantification and Source Evaluation," J. Constr. Eng. Manag., vol. 122, no. 1, pp. 55-60, 1996.

[19] H. P. H. Yuan and L. Shen, "Trend of the research on construction and demolition waste management.," Waste Manag., vol. 31, no. 4, pp. 670-679, Apr. 2010.

[20] Hong Kong Polytechnic and Hong Kong Construction Association, "Reduction of construction waste, Final report," 1993.

[21] R. M. Gavilan and L. E. Bernold, "Source Evaluation of Solid Waste in Building Construction," J. Constr. Eng. Manag., vol. 120, pp. 536-552, 1994.

[22] T. P. Pinto, "Material waste in traditional construction processes," 1989.

[23] V. W. Y. Tam and C. M. Tam, "A review on the viable technology for construction waste recycling," Resour. Conserv. Recycl., 2006.

[24] V. W. Y. Tam, D. Kotrayothar, and Y. C. Loo, "On the prevailing construction waste recycling practices: a South East Queensland study," Waste Manag. Res., 2009.

[25] A. Baldwin, C. S. Poon, L. Y. Shen, S. Austin, and I. Wong, "Designing out waste in high-rise residential buildings: Analysis of precasting methods and traditional construction," Renew. Energy, 2009.

[26] S. K. Lachimpadi, J. J. Pereira, M. R. Taha, and M. Mokhtar, "Construction waste minimisation comparing conventional and precast construction (Mixed System and IBS) methods in high-rise buildings: A Malaysia case study," Resour. Conserv. Recycl., vol. 68, pp. 96-103, 2012.

[27] J. Wang, Z. Li, and V. W. Y. Tam, "Critical factors in effective construction waste minimization at the design stage: A Shenzhen case study, China," Resour. Conserv. Recycl., 2014.

[28] T. Vivian W Y, T. C.M., and S. L.Y., "Comparing material wastage levels between conventional in-situ and prefabrication construction in Hong Kong," J. Harbin Inst. Technol. (New Ser., 2004.

[29] V. W. Y. Tam, C. M. Tam, S. X. Zeng, and W. C. Y. Ng, "Towards adoption of prefabrication in construction," Build. Environ., 2007. 
[30] L. Jaillon, C. S. Poon, and Y. H. Chiang, "Quantifying the waste reduction potential of using prefabrication in building construction in Hong Kong," Waste Manag., 2009.

[31] T. O. Adewuyi and I. A. Odesola, "Factors Affecting Material Waste on Construction Sites in Nigeria," J. Eng. Technol., vol. 6, no. 1, pp. 82-99, 2015.

[32] U. Aminu Umar, N. Shafiq, A. Malakahmad, M. Fadhil Nuruddin, and I. Umar Salihi, "Ranking of principal causes of construction waste for Malaysian residential project," in 3rd International Conference on Civil, Offshore and Environmental Engineering (ICCOEE ), 2016.

[33] L. L. Ekanayake and G. Ofori, "Construction material waste source evaluation," Proc. Strateg. a Sustain. Built Environ. Pretoria, 2000.

[34] G. L. Gara, A. R. Anis, and A. El Gammal, "Materials Waste in the Egyptian Construction Industry," Proc. 9th Annu. Conf. Int. Gr. Lean Constr., 2001.

[35] G. Polae and G. Ballard, "Waste in Turkish Construction: Need for Lean Construction Techniques," in 12th Annual Conference of the International Group for Lean Construction., 2004.

[36] T. Esin and N. Cosgun, "A study conducted to reduce construction waste generation in Turkey," Build. Environ., vol. 42, no. 4, pp. 1667-1674, Apr. 2007.

[37] D. De Vaus, Surveys in Social Research, 6th ed. London: Routledge, 2014.

[38] R. Carmichael, D. J. Edwards, and G. D. Holt, "Plant managers' perceptions of plant security systems," Eng. Constr. Archit. Manag., 2007.

[39] C. M. Tam, V. W. Y. Tam, J. K. W. Chan, and W. C. Y. Ng, "Use of Prefabrication to Minimize Construction Waste - A Case Study Approach,” Int. J. Constr. Manag., vol. 5, no. 1, pp. 91-101, 2005. 